\title{
Psycholinguistic Determinants of Meaning Formation in Students with Different Levels of Self-Disclosure
}

\author{
Svetlana Bezoluk ${ }^{1,}$, Elena Azarko ${ }^{1}$, Olga Derezko ${ }^{1}$, and Igor Kupriyanov ${ }^{1,2}$ \\ ${ }^{1}$ Don State Technical University, 1, Gagarin sq., 344003 Rostov-on-Don, Russia \\ ${ }^{2}$ Southern Federal University, 105/42, Bolshaya Sadovaya str., 344006 Rostov-on-Don, Russia
}

\begin{abstract}
The authors consider a meaning essay as a semantic technique, not only as convenient for any learning format (distance, full-time, mixed), but also as effective, capable of initiating the formation of students' meaning and launching a mechanism for comprehending the subject content at a deep, internal level. The formulation of an essay during the lesson at any of its stages, as well as as homework, is, according to the authors, a kind of «meaning task.» Delivered by the teacher or formulated by the students themselves at any level of learning, it is capable of activating the semantic sphere, launching the mechanism of «interest», comprehension. The authors conducted an empirical study using interdisciplinary methods of pedagogy and psychology: S. Jurard's self-disclosure questionnaire (modified version), psycholinguistic analysis of essays, content analysis of essay texts, statistical analysis - Student's t-test. technologies for the development of the semantic sphere of adolescents. The sample consisted of adolescents 12-15 years old (girls and boys) of secondary schools in Rostov-on-Don and the Moscow region. The novelty of this research lies in the use of the method of psycholinguistic analysis of meaning essays to assess the semantic sphere of adolescents.
\end{abstract}

\section{Introduction}

Considering the Word, according to the philosophical view of G. Shpet, as the beginning of knowledge, and the internal forms of words as semantic structures, we can assume that the words spoken inside «not aloud» and clothed in a sign form on paper, turn into an echo of our emotions, feelings, experiences, affecting our value-semantic sphere. In the age of digitalization, almost «unlearning», especially among the adult population, the skills of writing (after all, it is much faster to «speak» or type a text), it is the presentation of one's thoughts on paper, and especially by hand, that becomes almost a luxury. A change in the educational paradigm, when the cognitive «knowledge» approach is replaced by meaningoriented learning, which considers knowledge as a reflection of something that concerns myself specifically. These changes require researchers in the field of pedagogy to change also didactic approaches to learning. The search for new methods, ways of influencing the

* Corresponding author: sveta-ya7@ya.ru 
inner deep chords of students, bringing the significant to the surface, brings psychology and pedagogy closer and closer. In the era of uncertainty, the flexibility of the changing world, to teach not how this world works, but how to live and act in it. What technologies will be effective in the educational process and produce the desired results? Theseandotherissues are all relevant today.

Answering a number of questions raised above, as well as relying on initial developments, we will consider the «meaning essay» as one of the possible semantic techniques that initiate the meaning formation of students, a possible «problem on meaning» set by a teacher or independently by students, as a possible activator that triggers the mechanism of comprehension. In order to perform any action, it is necessary that it has a meaning for us. In the same way, writing an essay will make sense to us if it relates to something that is important to us, will be connected with something deep, will touch the deepest chords of our «Self». In the context of E-learning, the essay ceases to be just a formal activity of a student and a method of testing knowledge for a teacher, but becomes a way of influencing the semantic sphere by activating it. Deeply comprehended, it can bring the study to the level of «the very meaning of mine», and therefore become a «trigger of interest», the beginning of moving forward.

Denoting the definition of «meaning essay», under this term we will mean a form of presentation of our own thoughts, different from a mini-essay, based on our personal experience, having a free structure of presentation, characterized by an internal semantic unity, initiating the development of the meaning sphere of students [1].

\section{Analysis of publications}

The study is based on the philosophical understanding of the inner form of the word by G. G. Shpet [2].

The authors of this study relied on the fundamental works in the field of the psychology of meaning by D. A. Leontiev. The semantic sphere of personality includes the following components: personal meanings, meaning attitudes, meaning-forming motives-situational components and meaning constructs, meaning dispositions and values - the stable components [3]. One of the integral directions in psychological science at the present time is «meaning didactics», which reveals the didactic foundations of the formation and development of the meaning sphere of students. I. V. Abakumova reveals a holistic model of meaning-oriented learning - its goals, tasks, content. She identifies the criteria for the development of the meaning sphere of students: the concreteness of the relationship experienced by the subject to the implemented activity, the subjectivity of the relationship, the depth of the subject's relationship, the presence of the student's evaluative component. This allowed us to distinguish three levels of development of personal meanings: low, medium, and high [4]. Meaning didactics as a scientific, interdisciplinary discipline is reflected in the works of such researchers as: I. V. Abakumova, P. N. Ermakov, V. T. Fomenko, L. TsKagermazova, M. V. Godunov, I. A. Rudakova, V. M. Golubova, M. V. Gudkova, M. Yu. Konovalenko, I. E. Nesterenko, I. A. Rudakova, V. A. Slastenin, V. Ya. Stupakov, E. D. Fayzullayeva, D. V. Penkov, E. V. Shelyustyuk, K. Yu.Kolesina, A. A. Zelenov, E. S. Zorina, V. A. Savin, E. A. Pronenko. Currently, Russian psychology and pedagogy continue to conduct research aimed at systematizing scientific knowledge, forming a common solid system of didactic goals, principles, technologies, etc. The classification of the so-called «tasks for meaning» is quite well developed. N. Y. Zilberbrandt identifies the classification criteria: by the nature of meaning connections and by the sources of the statement [5]. E. S. Zorina presents the classification of «meaning techniques» as one of the components of meaning pedagogy [6]. The problem of typification and classification of tasks for meaning is complicated in connection with our constantly changing world, the world of 
«uncertainty», which manifests itself, according to D. A. Leontiev, «in three areas .... including in changing the status of values» [7]. L. Ts. Kagermazova in her article considers the initiation of meaning formation through meaning communications, and the educational process as a "group meaning-forming content» [8]. We agree with this statement, especially in the context of the digitalization of modern education, it is possible to consider remote interaction between a student and a teacher, designating it as a «meaning-generating digital environment» [9].

The methodological basis of this research is based on the fundamental works in the field of psycholinguistics by V. P. Belyanin. Based on the analysis of the text, in our case, the text of the «meaning essay», we can draw conclusions about the psychotype of the author, his emotional state [10]. The psycholinguistic analysis of the essay texts is based on the fundamental works in the field of psycholinguistics by A. A. Leontiev. For the empirical part of the study, the method of calculating psycholinguistic indicators of the Department of Applied Psychology of Kurgan State University was used as a basis. The Russian Scientific School at the Institute of Linguistics of the Russian Academy of Sciences annually holds round tables «Meaning formation in communication». Interesting are the reports of A.V. Vdovichenko and E. F. Tarasov, who, based on experiments, believe that verbal data taken from texts can have meaning-forming content only as a result of communication [13]. Pedagogical journals contain a lot of works devoted to the criteria, techniques, formats, and types of writing essays in various classes. For example, O. I. Sukhaninskaya in her article «Analysis of techniques that contribute to successful essay writing» examines essays in the Russian language lessons of one of the schools in Kazakhstan. But such works contain only a descriptive character, do not contain a meaning-forming context, without an emphasis on the semantic sphere of students [12]. A modified S. Jurard questionnaire was used to measure the dynamics of self-disclosure indicators. Research in in experimental psycholinguistics is diverse $[13,14,16,17,19,20,21,24,25,26]$. Some foreign researchers only indirectly touch upon the problems of this article. For example, Poldner, E. Simons, P. R. J. Wijngaards, G. Vanderschaaf, M. F. identified criteria for content analysis of reflexive essays among students of higher educational institutions. [13]. Interesting are the studies of Wilson J., who, based on the study of letters of students of grades 3-4, concludes about the level of achievement of students at the end of the year of educational programs [14], as well as studies of written expressions of the authors of the project for studying technical methods of written speech [15].

\section{Goal, objectives, and hypothesis}

The purpose of the study: to study the change in the features of the meaning-forming sphere of students aged 12-15 years during the use of the «meaning essay» technique. Tasks: on the basis of psycholinguistic analysis of the texts of «meaning essays» to characterize the features of the semantic sphere of adolescents, using the questionnaire of S. M. Jurard to document the level of self-disclosure of adolescents; to identify specific characteristics of adolescents with different levels of development of personal meanings in the educational process.

Hypothesis: 1) the technique of «meaning essay» can be one of mechanisms of influence and actualization of the meaning-forming sphere of adolescent students, 2) during the application of «meaning essay», there will be the activation and complication of the meaningforming sphere of adolescents and the formation of self-disclosure skills.

\section{Methods}


Methods from the fields of pedagogy and psychology: 1) writing a meaning essay with subsequent content analysis of the essay texts and highlighting the subtext according to the method of V. P. Belyanin; 2) to study the level of self-disclosure - the modified questionnaire of S. M. Jurard was used; 3) the psycholinguistic analysis of text according to the method of the Department of Applied Psychology of Kurgan State University; 4) statistical analysis Student's T-test (for paired and independent samples).

Teenagers were encouraged to write meaningful essays in history and social studies classes throughout the year. The essay topics were selected jointly by the teacher and the students as a result of general discussion. There were several topics to choose from, covering approximately the same subject content being studied. For example, «Choosing a profession: money or benefit to society?» or «Would I be able to produce something that does not profit me, but benefits people?». It should be noted that the teenagers were not offered the criteria for writing the text: the number of words, the disclosure of meaning of the statement, the theoretical and factual argumentation, that is, the criteria inherent in a standard essay. The idea was to build a speech statement based on the inner feelings of teenagers, self-disclosure of their deep potential, the creative component of writing. The task was set to answer the question as honestly as possible, to think well about the topic.

The essays were the objects of psycholinguistic analysis. Theindicatorsstudiedwere:

1. The indicator of the volume of speech output (the total number of words in the essay). This indicator in psycholinguistics gives evidence of the communicativeness, motivation, and personal characteristics of the author.

2. Average sentence size indicator (total number of words in the text/number of sentences). The higher the score, the higher the verbal intelligence. In the sentences of the classics, for example, this indicator can reach 30-35 words.

3. 3.The coefficient of vocabulary diversity (the number of different words $/ 2 *$ the total number of words in the text) in \%. It is fundamental in psychodiagnostics. Especially, as a result of a strong reaction to some events, emotions. In this case, the indicator decreases, and the number of repeated words increases.

4. Verbality coefficient (according to the formula: number of verbs in the text/number of words in the text) in \%. In another way, in psychodiagnostics, this indicator is called an indicator of aggressiveness. With the increase in the number of verb forms (participles, adverbs) in the text, thr conclusion is made about the excited state.

5. Coefficient of logical coherence (number of service words (conjunctions, prepositions $) / 3$ *number of words in the text). The harmonious structure of sentences, the coherence of the text are noted when the indicator is less than one.

6. The coefficient of embolism (clogging of the text - the number of emboli/total number of words) in \%. An important indicator - it demonstrates the richness of the lexical stock, the emotional state of the subject, indicates the level of speech culture, as well as the etiquette of the person.

For the convenience of semantic analysis of texts, the Advego program was used, which allows to quickly determine the number of unique words, the number of sentences and the semantic core.

\section{Results and discussion}

The empirical work was carried out in General education private schools in the Moscow region and Rostov-on-Don. The sample consisted of teenagers aged 12-15 years, studying in the 6th-8th grades of the Academy of arts in the number of 51 people ( 25 boys, 26 girls). A special feature of private schools is the small number of students in classes (7-10 people), and accordingly the ability of a teacher or psychologist to apply a particular technique, as well as note the results, also by direct observation. 
51 essays of students were studied, and the average indicators for each age subgroup of boys and girls were revealed. The analysis data is presented in table 1 . Commenting on the results, it can be observed that the indicators of the volume of speech production in girls are higher than in boys in both age subgroups. Girls have a higher indicator of the average size of sentences.

There is a noticeable difference in the volume of speech output both in girls aged 12-13 and 14-15 $\left(\mathrm{T}_{\mathrm{em} 2 \mathrm{~g}}=2.2\right.$ at $\mathrm{DFf}=24$ and $\left.\mathrm{T}_{0.01}=2.08\right)$, and in boys aged 12-13 and 14-15 $\left(\mathrm{T}_{\mathrm{em} 2 \mathrm{~b}}=3.1\right.$ at $\mathrm{DFf}=23$ and $\left.\mathrm{T}_{0.01}=2.81\right)$. This fact may indirectly indicate an increase in the level of speech production and verbal intelligence.

Table 1. Results of psycholinguistic analysis of the essay on the topic «Choosing a profession: money or benefit to society»

\begin{tabular}{|c|c|c|c|c|c|c|}
\hline \multirow[b]{2}{*}{$\begin{array}{l}\text { Indicatorsofps } \\
\text { ycholinguistic } \\
\text { analysis }\end{array}$} & \multicolumn{2}{|c|}{ Girls (26 pers.) } & \multicolumn{2}{|c|}{ Boys (25 pers.) } & \multirow[b]{2}{*}{$T_{\text {empG }}$} & \multirow[b]{2}{*}{$\mathbf{T}_{\text {emp }} \mathbf{b}$} \\
\hline & \begin{tabular}{|l}
$12-13$ \\
years \\
$(9$ pers. $)$
\end{tabular} & $\begin{array}{l}\text { 14-15years } \\
\text { (17 pers.) }\end{array}$ & $\begin{array}{l}12-13 \text { years } \\
(19 \text { pers. }\end{array}$ & $\begin{array}{l}\text { 14-15years } \\
\text { (6 pers.) }\end{array}$ & & \\
\hline $\begin{array}{l}\text { Speech output } \\
\text { volume } \\
\text { indicator }\end{array}$ & $79.1 \pm 21.6$ & \begin{tabular}{l|l}
5 & $84.7 \pm 39.6$
\end{tabular} & $57.4 \pm 13.0$ & $75.4 \pm 20.8$ & $\mathrm{~T}_{\mathrm{emp1g}}=0.4$ & $\begin{array}{c}\mathrm{T}_{\text {emplt }}=2.5 \\
*\end{array}$ \\
\hline $\begin{array}{l}\text { Average } \\
\text { sentence size }\end{array}$ & $13.5 \pm 3.1$ & $11.4 \pm 1.7$ & $9.1 \pm 2.1$ & $11.1 \pm 1.2$ & $\underset{* *}{\mathrm{~T}_{\mathrm{emp} 2 \mathrm{~g}}=2.2}$ & $\underset{* *}{\mathrm{~T}_{\mathrm{emp2b}}}=3.1$ \\
\hline $\begin{array}{l}\text { Coefficient of } \\
\text { vocabulary } \\
\text { diversity }\end{array}$ & $0.3 \pm 0.1$ & $0.3 \pm 0.1$ & $0.4 \pm 0.1$ & $0.3 \pm 0.1$ & $\mathrm{~T}_{\text {emp3g }}=1.5$ & $\mathrm{~T}_{\mathrm{emp} 3 \mathrm{~b}}=0.7$ \\
\hline $\begin{array}{l}\text { Verbality } \\
\text { coefficient }\end{array}$ & $16.4 \pm 3.5$ & $14.0 \pm 2.1$ & $17,2 \pm 3,1$ & $17.2 \pm 4.0$ & $\begin{array}{c}\mathrm{T}_{\mathrm{emp} 4 \mathrm{~g}}=2.1 \\
* *\end{array}$ & $T_{\text {emp } 4 b}=0$ \\
\hline $\begin{array}{l}\text { Coefficientoflo } \\
\text { gicalcoherence }\end{array}$ & $0.8 \pm 0.6$ & $1.2 \pm 0.4$ & $0,6 \pm 0,3$ & $1.0 \pm 0.5$ & $\begin{array}{c}\mathrm{T}_{\mathrm{emp5g}}=2.1 \\
* *\end{array}$ & $\mathrm{~T}_{\text {emp } 5 \mathrm{~b}}=1.9$ \\
\hline $\begin{array}{l}\text { Embolism } \\
\text { coefficient }\end{array}$ & $2.9 \pm 0.9$ & $2.7 \pm 4.3$ & $3,0 \pm 1,3$ & $3.3 \pm 1.5$ & $\underset{4}{\mathrm{~T}_{\text {empodg }}}=0$ & $\mathrm{~T}_{\text {emp } 6 \mathrm{~b}}=0.5$ \\
\hline
\end{tabular}

Note: marked with $* \mathrm{p}<0,05 ; *^{*}-\mathrm{p}<0,01$; for female teenagers $\mathrm{n}=26$ and $\mathrm{df}=24$ critical value $\mathrm{T}_{0,05}=2.06 \mathrm{~T}_{0,01}=2.08$; for male teenagers $\mathrm{n}=25$ and $\mathrm{df}=23$ critical value $\mathrm{T}_{0,05}=2.07 \mathrm{~T}_{0,01}=2.81$

At the same time, the level of sentence extension (the average size of sentences) decreases, in girls with age, and in boys, on the contrary, it increases. The coefficient of vocabulary diversity is about the same both in girls age groups 12-13 years and 14-15 years $\left(\mathrm{T}_{\mathrm{em} 3 \mathrm{~g}}=1,5\right.$ reaches critical values for $\mathrm{Df}=24$ and $\mathrm{T}_{0,05}=2.06$ ), and in the boys also remains at the same level $\left(\mathrm{T}_{\text {emp } 3 \mathrm{~b}}=0,7\right.$ does not reach critical values for $\mathrm{Df}=23$ and $\left.\mathrm{T}_{0,05}=2.07\right)$.

It is necessary to note the indicators of the verbality coefficient (the share of verbs). In the texts of boys, the number of verbs is much higher than in the texts of girls in both age groups. In the texts of essays, it does not exceed $22 \%$, which indicates a relatively calm state of the authors.If the coefficient of verbality in the texts of students begins to increase, this may indicate an excited state of the author. The coefficient of embolism (blockage) of texts in boys is higher than in texts in girls. Moreover, when comparing indicators in groups, this coefficient decreases in girls, while in boys it increases. To study changes in the level of self- 
disclosure of students at the beginning and end of the year, a questionnaire was used, which is a modification of the questionnaire by Jurard S. M., which allows you to identify the student's ability to self-disclosure.

The data is presented in table 2 . At the beginning of the year, it can be observed that a higher level of self-disclosure is observed in girls aged 14-15 years (21.88 \pm 5.7$)$ and in boys aged 12-13 years (21.89 \pm 7.3 ). Discussing the results, with immaturity of brain functions in children or disorders of the parts of the brain, a decrease in speech productivity is observed $[22,23,24,27]$.

Table 2. Results of the study of the level of self-disclosure of students

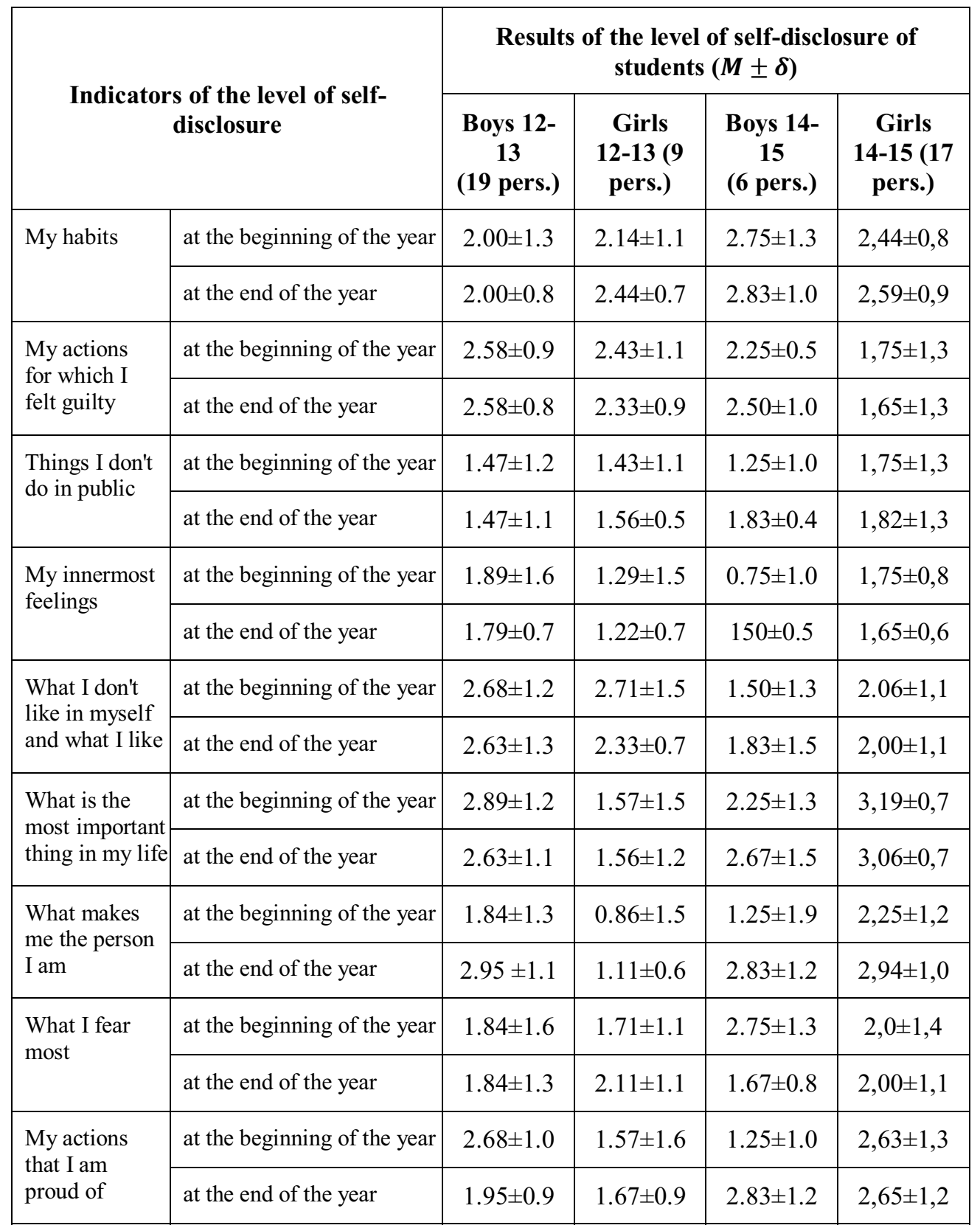




\begin{tabular}{|r|l|c|c|c|c|}
\hline $\begin{array}{l}\text { My close } \\
\text { relationships } \\
\text { with people }\end{array}$ & at the beginning of the year & $2.00 \pm 1.4$ & $2.29 \pm 1.5$ & $0.75 \pm 1.0$ & $2,06 \pm 1,1$ \\
\cline { 2 - 7 } & at the end of the year & $1.95 \pm 0.4$ & $2.00 \pm 0.9$ & $2.83 \pm 1.6$ & $1,71 \pm 0,8$ \\
\hline $\begin{array}{r}\text { Total self- } \\
\text { disclosure } \\
\text { level: }\end{array}$ & at the beginning of the year & $21.89 \pm 7.3$ & $18.00 \pm 5.8$ & $16.75 \pm 6.6$ & $21,88 \pm 5,7$ \\
\cline { 2 - 7 } at the end of the year & $21.79 \pm 3.6$ & $18.33 \pm 2.5$ & $23.33 \pm 6.0$ & $22,06 \pm 4,5$ \\
\hline \multicolumn{1}{|c|}{ (for paired samples) } & $\begin{array}{c}\mathrm{T}_{\mathrm{b} 12}=0.1 \\
\mathrm{~T}_{0.05}=2.1 \\
\text { and } \\
\mathrm{T}_{0.01}=2.88\end{array}$ & $\begin{array}{c}\mathrm{T}_{\mathrm{g} 12}=0.6 \\
\mathrm{~T}_{0.05}=2.34 \\
\text { and } \\
\mathrm{T}_{0.01}=3.36\end{array}$ & $\begin{array}{c}\mathrm{T}_{\mathrm{b} 14}=0.2 \\
\mathrm{~T}_{0.05}=2.12 \\
\text { and } \\
\mathrm{T}_{0.01}=2.92\end{array}$ & $\begin{array}{c}\mathrm{T}_{\mathrm{g} 14}=1.5 \\
\mathrm{~T}_{0.05}=2.57 \\
\text { and } \\
\mathrm{T}_{0.01}=4.03\end{array}$ \\
\hline
\end{tabular}

The girls aged 14-15 years were willing to share such information about themselves, like «what in life is most important to me» $(3,19 \pm 0,7)$, «my actions and things I'm proud of» $(2,63 \pm 1,3)$ and «about my habits» $(2,44 \pm 0,8)$, and such topics as «my actions for which I experienced a feeling of guilt» $(1,75 \pm 1,3)$, «my feelings» $(1,75 \pm 0,8)$ and «what I don't do in public" $(1,75 \pm 1,3)$ appeared in the list of less preferred topics.

It should be noted that boys 12-13 years more actively ready to talk with others about what's most important in their lives $(2,89 \pm 1,2)$, and what they like in themselves and their actions that they are proud of $(2,68 \pm 1.0$ and to $2.68 \pm 1,2)$, about the experience of guilt $(2,58 \pm 0,9)$. Boys aged 12-13 years are least likely to disclose information about what they do not do in public $(1.47 \pm 1.2)$, their fears $(1.84 \pm 1.6)$, "what makes me what I am"(1.84 \pm 1.3$)$, and their innermost feelings (1.89 \pm 1.6$)$.

A lower level of self-disclosure at the beginning of the year is in boys aged 14-15 years (16.75 \pm 6.6$)$. They are willing to share information about themselves with others about their habits $(2.75 \pm 1.3)$ and fears $(2.75 \pm 1.3)$, about what is most important in life, about their actions $(2.25 \pm 1.3)$.

The lowest level of self-disclosure is found in girls $12-13$ years $(18,00 \pm 5,8)$, they are more likely to trust others with information about themselves, the next topic - "what I don't like in myself and what I like" $(2,71 \pm 1,5)$, "my actions for which I experienced a feeling of guilt" $(2,43 \pm 1,1)$, "my close relationships" $(2,29 \pm 1,5)$. Least of all girls $12-13$ years were willing to share with others the following topics - "what makes me what I am" $(0,86 \pm 1,5)$, "my feelings" $(1,29 \pm 1,5)$,and "what in life is most important to me» $(1,57 \pm 1,5)$ and "my actions, that I'm proud of" $(1,57 \pm 1,6)$.

At the end of the year, repeated diagnostics showed that the level of self-disclosure in boys aged 12-13 years slightly decreased (from $21.89 \pm 7.3$ to $21.79 \pm 3.6$ ). The preferred topics for confidential communication with other people have practically not changed compared to the beginning of the year - they are still ready to talk with others about the most important things in their life (2.63 \pm 1.1$)$ and about experiencing feelings of guilt $(2.58 \pm 0.8)$, as well as about "what I don't like about myself and what I like" (2.63 \pm 1.3$)$. The following topics are least likely to be discussed: "what I don't do in public" $(1.47 \pm 1.1)$, "my innermost feelings" (1.79 \pm 0.7$)$, "what I fear most"(1.84 \pm 1.6$)$.

According to the level of self-disclosure in girls aged 14-15, the results changed slightly from 21.88 at the beginning to 22.06 at the end of the year. Also, as in the beginning of the year, most girls are willing to share such information about themselves, like "what in life is most important to me" $(3,06 \pm 0,7)$, "what makes me what I am" $(2,94 \pm 1,0)$ and "my actions that I am proud of" $(2,65 \pm 1,2)$. Girls aged 14-15 are not ready to open up to others about the following topics: «my actions for which I felt guilty» $(1.65 \pm 1.3)$ «my innermost feelings» $(1.65 \pm 0.6)$ and «my close relationships with people» $(1.71 \pm 0.8)$.

In boys aged 14-15, the level of self-disclosure significantly increased (from $16.75 \pm 6.6$ to $23.33 \pm 6.0$ ). More young men are willing to trust information about their habits $(2,83 \pm 1,0)$, 
about the close relations with people $(2,83 \pm 1,6)$, "my actions, the things I'm proud of" $(2,83 \pm 1,2)$, "what makes me what I am" $(2,83 \pm 1,2)$, about what in life is most important $(2,67 \pm 1,5)$ and about actions for which they feel guilty $(2,50 \pm 1,0)$. "My innermost feelings" $(1.50 \pm 0.5 \pm 1.0)$ is the category that young men aged $14-15$ are least ready to share with others.

Girls aged 12-13 showed a low level of self-disclosure, both at the beginning of the year 18.00 and at the end of the year 18.33. The categories in which girls are ready for selfdisclosure at the end of the year are: «my habits» $(2.44 \pm 0.7)$ «my actions for which I felt guilty» (2.33 \pm 0.9$)$, «what I don't like about myself and what I like» (2.33 \pm 0.7$)$. Least of all they are ready to discuss the following topics: «what makes me what I am» $(1,11 \pm 0,6)$, «my feelings» $(1,22 \pm 0,7)$, «what in life is most important to me» $(1,56 \pm 1,2)$, «what I don't do in public» $(1,56 \pm 0,5)$.

Table 2 shows that the level of self-disclosure increased more in adolescents aged 14-15 years (changes are insignificant - $\mathrm{T}_{\text {emp }}$ does not reach the critical values of $\mathrm{T}_{0.05}$ and $\mathrm{T}_{0.01}$ ).

The following shows the empirically registered results of the features of the meaning sphere (motives, personal meanings, attitudes, dispositions, construct, personal values). The content analysis was based on the results of meaning essays of teenagers of the studied schools. It is necessary to re-pay attention to the specifics of private school students, usually, from middle-income and above-average families, as well as to the specifics of the topics of meaning essays: «Would I be able to produce something that benefits people but doesn't profit me»/ «Choice of profession: money or benefit to people». Based on the method of V.P. Belyanin, the authors selected subtext (hidden information) from the text. Examples are excerpts from texts of teenagers (girls and boys) with different levels of self-disclosure that most clearly reflect the meaning components. The data is presented in table 3 .

Table 3. Results of content analysis of semantic sphere features

\begin{tabular}{|c|c|c|}
\hline \multicolumn{3}{|c|}{ Motive } \\
\hline $\begin{array}{l}\text { Boy, } 14 \text { years old, Moscow } \\
\text { region, the level of self- } \\
\text { disclosure is below average, the } \\
\text { volume of speech output is } 100 \\
\text { words, the verbality coefficient is } \\
\text { increased by } 22 \% \text {. }\end{array}$ & $\begin{array}{l}\text {...I believe that you need to earn money } \\
\text { initially for yourself in order to at least } \\
\text { keep my family... }\end{array}$ & $\begin{array}{l}\text { motive of debt and } \\
\text { responsibility }\end{array}$ \\
\hline $\begin{array}{l}\text { Boy, } 14 \text { years old, Moscow } \\
\text { region, self-disclosure level is } \\
\text { low, speech output is } 36 \text { words. }\end{array}$ & $\begin{array}{l}\text {... I could bake bread products and give } \\
\text { them away for free.. }\end{array}$ & achievement motive \\
\hline $\begin{array}{l}\text { Girl, } 13 \text { years old, Moscow } \\
\text { region, self-disclosure level } \\
\text { below average, speech output } \\
\text { volume } 93 \text { words }\end{array}$ & $\begin{array}{l}\text {... On the one hand, I will help people } \\
\text { and they will be happy and I will later, } \\
\text { for what I did good. On the other hand, } \\
\text { I will have a certain amount and it will } \\
\text { slowly decrease... }\end{array}$ & $\begin{array}{l}\text { Motive of avoiding } \\
\text { failure and avoiding } \\
\text { choice }\end{array}$ \\
\hline \multicolumn{3}{|c|}{ Meaning disposition } \\
\hline $\begin{array}{l}\text { Girl, } 13 \text { years old, Rostov-on- } \\
\text { don, average level of self- } \\
\text { disclosure, volume of speech } \\
\text { output-122 words. }\end{array}$ & $\begin{array}{l}\text {...I believe that I would be unlikely to } \\
\text { produce something that benefits people } \\
\text { but does not benefit me.... for example, } \\
\text { my company produces food } \\
\text { (confectionery), but almost all the } \\
\text { income of my company goes to another }\end{array}$ & $\begin{array}{l}\text { Understanding the } \\
\text { diversity of labor } \\
\text { relations } \\
\text { situations (employees } \\
\text { can be in two } \\
\text { companies at the }\end{array}$ \\
\hline
\end{tabular}


company, because employees of another company make products of my company working for my company. Yes, it sounds strange, but of course this can happen

in real life.But it seems to me that why should I do something that does not benefit people, but does not bring profit to me? I would do something that would benefit people and definitely make a profit for me. For example, I will give clients a make-up, they will pay me for the service, respectively, it will bring profit to me, and it will benefit people! Profit for yourself is always important!

$O R$

Girl, 13 years old, Moscow region, self-disclosure level below average, speech output 93 words
.... On the one hand, I will help people and they will be happy and I will later, for what I did good. On the other hand, I will have a certain amount and it will slowly decrease and at one point it will run out, I will not have any money left. For example, a person bakes bread and rolls for people, but does not make a profit from it. His money is running out, he spent everything on groceries. The products will run out, and he will not be able to produce anything. Another disadvantage of this is that you can not provide for yourself. CONCLUSION: this question is controversial, but I probably could not!... same time);
understanding the
social roles of the
Employer (managing
the company) and the

Employee (providing production);

predestination of the link: service-moneyprofit

General doubt (good and joy to people at the risk of closing production and being unable to provide for themselves);

evaluating herself as unable to combine benefits and money; avoiding choice.

\section{Meaning construct}

Boy, 14 years old, Moscow region, the level of selfdisclosure is below average, the volume of speech output is 100 words, the verbality coefficient is increased by $22 \%$.

Boy, 13 years old, Moscow region, self-disclosure level average, volume of speech output 60 words.
... I believe that you need to earn money initially for yourself in order to at least keep my family. And when will I feel confident knowing that I can help my family and even friends in the first place, then I will not refuse to help the people later. Because it will be nice for me and for them.

\section{$O R$}

... believe that it is necessary to combine both money and benefits... in $80 \%$ of cases, money is important to me.... doctor and teacher professions will become very rare... they will become more highly paid .... the remaining 20\%-I choose benefits...
From personal confidence in his own economic well-being to the well-being of other people; building priorities; understanding the rootcause.

you need to combine both money and benefits; the uniqueness professions 
Girl, 14 years old, city of.Postovon-don, level of self-disclosure is average, the volume of speech output is 101 words.

Girl, 14 years old, Moscow region, above-average selfdisclosure level, speech output volume of 198 words.
...I want a job that I will enjoy... and money and benefits to society are secondary to me... What do I care about society? What will I gain from the benefits to society? What, everyone will come up and say thank you? No...

$O R$

...I believe that if a person does what they love, they don't care how much they get paid for it, or if they get paid at all...This business interests him so much that he does not think about money and profit, he wants to create all the time and immerse himself in his favorite work...I would be able to give dance lessons, even if I earned a penny... Happiness is not in money, happiness is in life and in favorite job...
When I invest in people, I expect a return; for everything I do, I want to hear approval; combination benefit and profit.

passion for what you love; desire to get positive emotions

\section{Personal value}

Boy, 14 years old, Moscow region, low level of selfdisclosure, volume of speech output 36 words.

Boy, 13 years old, Moscow region, level of self-disclosure is average, the volume of speech production is 65 words, the embolism coefficient is increased.
...Yes, I could, because I like to make people happy. I could bake bread products and give them away for free, I could send money to charity, because there this money will be sent to a good cause

\section{OR}

...I believe that a person cannot live without money, but it is also wrong not to do good to society. There are people who devote their whole lives to this, for example, a policeman, a teacher, a doctor... To be honest, I've always been amazed by this! I don't understand how you can give benefit to strangers instead of a lot of money, okay charity, but I wouldn't be able to donate a lot of money to other people...
Value rating: 1-joy of other people, 2-selflessness, 3-faith in good intentions

Value rating: 1 - material values, namely money, 2-own well-being .

According to I.V. Abakumova's research one can distinguish three levels of development of personal meanings in the educational process: low, medium, and high. Further are the texts of meaning essays by teenagers (boys and girls) are classified and common typical features of each level of development of the meaning sphere are identified.

Low: Indifferent attitude of a student, lack of stimulation needs, indifference to the phenomena and facts being studied, to the learning process itself. Texts, as a rule, have a small indicator of the volume of speech production (up to 50 words); there is no clear position, there is a lack of desire to think; there may be cases of plagiarism of texts

Frequently found quotes:...For me, it's both... (D, 13 years old)

...I do not know how to answer this question... (M, 12 years old)

...I don't care... (D, 13 yearsold) 
...why should I think about it.. I don't need it... (M., 14 years old)

...I choose the profession of a doctor, now everyone praises them... (M, 13 years old)

Average: A rather pronounced state of the personal-meaning sphere, the revealed meanings are fragmentary, consciousness has no conceptual base. Texts have average indicators of the volume of speech production (50-80); the embolism coefficient is increased (more than 3\%); the coefficient of logical coherence is increased due to the increase in the number of service words; avoiding choice or hesitation; reproductive approach (I do it on the model of a regular mini-composition).

Frequently found quotes:...I think this is a very difficult question...(M., 13 years old) ...it would seem that this is an easy question, and it could be answered without difficulty, but no....(D, 14 years old $)$

...in principle, this is possible...( $\mathrm{D}, 13$ years old $)$

...this question is controversial, but I probably wouldn't be able to...(D., 14 years old)

...doctors, teachers benefit people...(D, 13 years old)

High: Integrity of personal and semantic formations. Views have the character of beliefs, worldviews. Indicators of the volume of speech output are above average (above 80 words); high connectivity, reasonableness; low indicators of the embolism coefficient; as a rule, there is a clear position or reasoned choice from several sides; non-standard (creative) approach to solving the problem; there is the desire to engage in a certain type of activity.

Frequently found quotes: ...I have always been amazed at how you can benefit people without getting money... (M, 12 years old)

... personally, I am not going to devote my life to the benefit of society... (D, 15 years)

...I thought and came to the conclusion that it is possible to combine money for the benefit of society... (M, 14 years old)

... you can become an actress, earn money and benefit society ... (D, 14 years old)

...Neither money, nor benefit to society... This is definitely ... (D, 13 years old)

The data of content analysis of the texts of meaning essays allowed us to conclude that it is possible to empirically register the components of the semantic sphere of adolescents. Based on the classification of levels of development of personal meanings, to classify the studied texts into three groups and to highlight the general characteristics of each of them.

The connection of language abilities, cognitive processing and comprehension is noted [20-22].

\section{Conclusions and future directions}

The study allowed us to draw conclusions:

1. A meaning essay is an effective meaning technique that can bring what is being studied to a personal level, a kind of " task for meaning» that initiates the formation of meaning in students.

2. Psycholinguistic analysis of texts showed the difference in figures of speech production among girls and boys in the two age subgroups: the girls $12-13$ years $(79,1 \pm 21,6)$, the girls $14-15$ years(and $84.7 \pm 39,6$ ), the boys $12-13$ years $(57,4 \pm 13,0)$, the boys $14-15$ years $(75,4 \pm 20,8)$; increased verbality coefficient in boys in both age groups(12-13 years of $17.2 \pm 3,1,14-15$ years of $17.2 \pm 4,0)$ compared to girls, $12-13(16,4 \pm 3,5)$ and $14-15$ years $(14,0 \pm 2,1)$. The coefficient of embolism (blockage) of texts of boys is higher than in texts of girls. Moreover, when comparing the indicators in the groups of girls, this coefficient

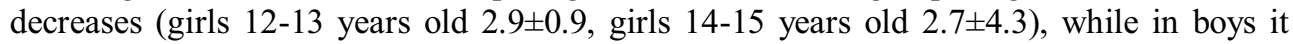
increases (boys 12-13 years old 3.0 \pm 1.3 , boys $14-15$ years old $3.3 \pm 1.5$ ).

3. Over the year there have been changes in the level of self-disclosure in teenagers: the girls 12-13 years $(18,00 \pm 5.8$ beginning of the year to $18.33 \pm 2.5$ in the end of the year); the girls of 14-15 years (of $21.88 \pm 5,7$ at the beginning of the year to $22.06 \pm 4.5$ in the end of the year); 
in boys 12-13 years( of $21.89 \pm 7,3$ at the beginning of the year to $21,79 \pm 3,6$ in tonce year); boys $14-15$ years $(16,75 \pm 6,6$ at the beginning of the year to $23,33 \pm 6,0$ at the end of the year). 4. In the content analysis of essays, an attempt is made to identify the motives, personal meanings, semantic dispositions, constructs, and personal values of students. Teenagers aged 12-13 are characterized by the presence of motives for avoiding failure and achievement, sufficiently developed personal meanings associated with the experience of pleasant emotions (pleasure, joy, confidence), and meaning dispositions begin to appear in the essays of individual adolescents. Teenagers of 14-15 years are characterized by a more developed state of the semantic sphere - the appearance of the motive of duty and responsibility; there are semantic dispositions (understanding of the diversity of employment relationships and situations, avoiding the choice, the general hesitation); in essays of individual adolescents semantic constructs begin to appear; in general the individual values can be traced or their complexes of 2-4 values: joy to others in the first place in some adolescents and money, material value in other teenagers of the same age. Studying the peculiarities of the semantic sphere of adolescents requires a larger sample and a large-scale study.

5. The specificity of the texts of meaning essays of students with different levels of development of personal meanings in the educational process is revealed (according to I.V. Abakumova):

- texts of teenagers with a low level of development of personal meanings and underdevelopment of the meaning-forming sphere have a small indicator of the volume of speech production (up to 50 words), they do not follow a clear position of the author, there are cases of plagiarism of texts;

- texts of adolescents with an average level of development of the personal and semantic sphere have average indicators of the volume of speech production (50-80), the embolism coefficient is increased (more than 3\%), the coefficient of logical coherence is increased due to an increase in the number of service words, avoiding the choice or hesitation, and a reproductive approach (on the model of a regular mini-essay);

- in the texts of adolescents with a high level of development of the meaning-forming sphere

- the volume of speech production is above average (above 80 words), high connectivity, argumentation, low indicators of the embolism coefficient, there is a clear position or reasoned choice of the author from several sides, a non-standard (creative) approach to solving the problem, the desire to engage in a certain type of activity is traced.

6. This study has shown that the meaning essay is a didactic device that activates the meaning sphere and can be recommended in the work of teachers, psychologists of educational institutions of various types.

\section{References}

1. S. Bezoluk, E. Azarko, V. Sannikova, O. Derezko, The initiation of the students' meaning formation via the meaning essay E3S Web Conf. 210, 18059 (2020) DOI: $10.1051 / \mathrm{e} 3 \mathrm{sconf} / 202021018059$

2. G.G. Shpet, The Internal Form of the Word: Etudes and Variations on Humboldt's themes, 216 (Moscow: Komkniga, 2016)

3. D. A. Leontiev, Psychology of meaning: nature, structure and dynamics of semantic reality (Moscow: Smysl, 2019)

4. I. V. Abakumova, A. M. Kukular, V. T. Fomenko, Meaning-didactics as a systemic embodiment of a general theory of meaning in the practice of the educational process. Russian psychological journal, 11(3), 24-32 (2014) DOI: https://doi.org/10.21702/rpj.2014.3.2 
5. N. Yu. Zilberbrand, Didactic essence of meaning tasks, Bulletin of Cherepovets state University 4, 106-109 (2013)

6. E.S. Zorina, I. S. Dyshlyuk, Effective semantic techniques in the practice of the educational process (Rostov-on-Don, Feniks, 2016)

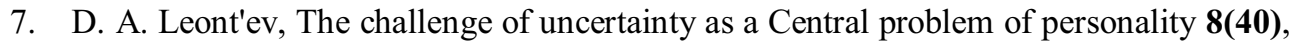
$2(2015)$

8. L. Kagermazova, TS Semantic communications as a type of interaction between teachers and students in "our new school», Russian psychological journal 11(3), 49-57 (2014)

9. S. P. Bezoluk, Meaning formation as a component of the development of digital competencies of adolescents, 12, 41-52 (2020)

10. V. P. Belyanin, Psychological linguistics. Text as a reflection of the inner worlds of the author and the reader, 320 (Moscow: Genezis, 2016).

11. A.V. Vdovichenko, E.F. Tarasov, Verbal data as part of a communicative action: language, text, author, interpreter 4(34), 22-39 (2017)

12. U.I. Sukhanova, Analysis of techniques contributing to successful essay writing, School pedagogy 1, 57 (2017)

13. E. Poldner, P.R.J. Simons, G. Wijngaards, van der M.F. Schaaf, Quantitative content analysis procedures to analyse students' reflective essays: A methodological review of psychometric and edumetric aspects. Educational Research Review Elsevier Ltd. Retrieved February 7(1), 19-37 (2012)

14. J. Wilson, Universal screening with automated essay scoring: Evaluating classification accuracy in grades 3 and 4, Journal of School Psychology 68, 19-37 (2018) https://doi.org/10.1016/j.jsp.2017.12.005

15. J. Elwood Romig, A. A. Miller, W. J. Therrien, J. W. Lloyd, Meta-Analysis of Prompt and Duration for Curriculum-Based Measurement of Written Language. UniversityofTexasatArlington, Exclusivity, (2020) DOI: 10.1080 09362835.2020.1743706

16. B. MacWhinney, Neuroemergentism: Levels and constraints, Journal of Neurolinguistics 49, 232-234 (2019) https://doi.org/10.1016/j.jneuroling.2018.04.002

17. B. MacWhinney, Psycholinguistics: Overview, International Encyclopedia of the Social \& Behavioral Sciences (Second Edition), 353-358 (2015) https://doi.org/10.1016/B9780-08-097086-8.57010-X

18. A.N. Katz, K.A. Hussey, Psycholinguistics, in Encyclopedia of Creativity (Second Edition), 271-278 (2011) https://doi.org/10.1016/B978-0-12-375038-9.00185-0

19. O. Bott, P. Augurzky, W. Sternefeld, R. Ulrich, Incremental generation of answers during the comprehension of questions with quantifiers, Cognition 166, 328-343 (2017) https://doi.org/10.1016/j.cognition.2017.05.023

20. S. E. Brennan, A. Galati, A. K. Kuhlen, Two Minds, One Dialog: Coordinating Speaking and Understanding, Psychology of Learning and Motivation 53, 301-344 (2010) https://doi.org/10.1016/S0079-7421(10)53008-1

21. J. F.Kroll, P. E. Dussias, C. A. Bogulski, J. R. Valdes Kroff, Juggling Two Languages in One Mind: What Bilinguals Tell Us About Language Processing and its Consequences for Cognition, in Psychology of Learning and Motivation 56, 229-262 (2012) https://doi.org/10.1016/B978-0-12-394393-4.00007-8

22. B. Hemforth, B. Mertins, C. Fabricius-Hansen, Psycholinguistic Approaches to Meaning and Understanding across Languages, Springer International Publishing, 251-258 (2014) 
23. https://www.researchgate.net/publication/284454518_Psycholinguistic_Approaches_to _Meaning_and_Understanding_across_Languages (Last accessed 2021/12/03)

24. O. María, A. de la Rosa, Evaluation of emotional and psycholinguistic problems in deaf and hard-of-hearing students in the Canary Islands, Heliyon 7(3), e06446 (2021) https://doi.org/10.1016/j.heliyon.2021.e06446

25. R.S.W. Alyahya, A. D.Halai, P. Conroy, M. A. L. Ralph, Mapping psycholinguistic features to the neuropsychological and lesion profiles in aphasia, Cortex 124, 260-273 (2020) https://doi.org/10.1016/j.cortex.2019.12.002

26. P. Monaghan, S. G. Roberts, Cognitive influences in language evolution: Psycholinguistic predictors of loan word borrowing, Cognition 186, 147-158 (2019) https://doi.org/10.1016/j.cognition.2019.02.007

27. N. B. Ratner, J. Berko Gleason, Psycholinguistics, Reference Module in Neuroscience and Biobehavioral Psychology, 1199-1204 (2017) https://doi.org/10.1016/B978-0-12809324-5.22185-8

28. J. Arabski, A. Wojtaszek, Neurolinguistic and Psycholinguistic Perspectives on SLA, Studies in Second Language Acquisition 33(1), 144-145 (2011) DOI: https://doi.org/10.1017/S0272263110000665 